\title{
É TEMPO DE ESPERANÇAR: contribuições da epistemologia freireana na/para uma formação continuada
}

\author{
Mariana dos Santos Cezar \\ Samuel Rocha de Oliveira
}

\section{Resumo}

Este artigo tem por objetivo descrever como um processo de formação continuada pode ser construído a partir de uma (re)leitura da epistemologia freireana e do trabalho desenvolvido nos círculos de cultura. Esta investigação tem abordagem qualitativa, desenvolvida com cinco docentes dos anos iniciais do Ensino Fundamental de uma escola estadual de São Paulo. Nesta pesquisa, foi estabelecida uma ação de formação na qual, ao longo de quinze encontros, pesquisadora e participantes dialogaram a respeito de temas que foram identificados nas falas das participantes, ao descreverem as situações vivenciadas por elas no contexto escolar. Os dados produzidos foram interpretados à luz da Análise Dialógica do Discurso, oriunda dos estudos bakhtinianos. Os resultados mostram que construir uma formação continuada, com base nos pressupostos da epistemologia freireana, pode viabilizar uma tomada de consciência da realidade, por meio da superação de uma visão acrítica acerca das situaçoes-limite vivenciadas no contexto escolar, bem como o desenvolvimento de atos-limites para a superação dessas situações e para a construção de uma consciência crítica.

Palavras-chave: epistemologia freireana; educação libertadora; formação continuada; diálogo; conscientização.

IT IS TIME TO HOPE: contributions of Freire's epistemology in/for in-service education

\section{Abstract}

This article aims to describe how an in-service education process can be built from a (re)reading of Freire's epistemology and the work developed in cultural circles. This investigation has a qualitative approach, developed with five teachers of a state early years elementary school in São Paulo. In this research, a training action was established in which, during fifteen meetings, the researcher and participants dialogued about themes that were identified in the speeches of the participants, when describing the situations experienced by them in the school context. The data produced were interpreted from the Dialogic Discourse Analysis viewpoint, derived from Bakhtinian studies. The results show that building an in-service education based on the assumptions of Freire's epistemology can make it possible to become aware of reality, by overcoming an uncritical view of the at-the-edge-situations experienced in the school context, as well as the development of limit-action to overcome these situations and to build a critical conscience.

Keywords: freirean epistemology; liberating education; in-service education; dialogue; awareness.

ES HORA DE ESPERANZAR: contribuciones de la epistemología de Freire en/para la educación continua

\section{Resumen}

Este artículo tiene como objetivo describir cómo se puede construir un proceso de educación continua a partir de una (re) lectura de la epistemología de Freire y del trabajo desarrollado en los círculos culturales. Esta investigación tiene un enfoque cualitativo, desarrollado con cinco profesores de los primeros años de 
la escuela primaria en una escuela estatal de São Paulo. En esta investigación se estableció una acción formativa en la que, a lo largo de quince encuentros, la investigadora y los participantes dialogaron sobre temas que fueron identificados en los discursos de los participantes, al describir las situaciones vividas por ellos en el contexto escolar. Los datos producidos se interpretaron a la luz del análisis del discurso dialógico, derivado de los estudios bakhtinianos. Los resultados muestran que construir una formación continua, a partir de los supuestos de la epistemología de Freire, puede posibilitar una toma de conciencia de la realidad, superando una visión acrítica de las situaciones límite vividas en el contexto escolar, así como el desarrollo de acciones -límites para la superación estas situaciones y para crear conciencia crítica.

Palabras clave: epistemología de Freire; educación liberadora; educación continua; diálogo; conciencia.

\section{PRIMEIRAS PALAVRAS}

É tempo de esperançar! Esperançar não no sentido da esperança de quem espera, de quem aguarda, mas no sentido de quem se move, de quem busca (FREIRE, 2007). Quando afirmamos que é tempo de esperançar, estamos dizendo que é tempo de transformar, de buscar novos caminhos e novas possibilidades.

O tema esperança é uma das categorias centrais da epistemologia freireana, e se relaciona com outros conceitos, como utopia ${ }^{1}$ e sonho. Nessa epistemologia, a esperança, a utopia e o sonho são tratados como sinônimos e partem do princípio de que conhecer é a possibilidade de buscar, de romper as barreiras entre o ser e o ser mais ${ }^{2}$. Essa busca se insere na perspectiva ontológica do ser que, como um ser inacabado, inconcluso, busca a conclusão e o aprimoramento, esforçandose para se constituir como ser mais, porque tem a esperança de que essa busca não é vão. Nessa perspectiva, a esperança é um imperativo histórico, pois, como seres da esperança, mulheres e homens estão defronte da possibilidade de mudar o presente e de elaborar outro futuro. Assim, "[a] esperança baseada na ação impede tanto a acomodação pragmática à realidade quanto a fuga para idealismos incapazes de interferir na história” (STRECK, 2019, p. 199).

Quando falamos que é tempo de esperançar e voltamos o nosso olhar para a formação continuada de professores, estamos pensando nas possibilidades de mudança que podemos efetuar nesses espaços de formação. Isso porque, em tempo de esperançar, a formação continuada precisa ser construída em coletividade com os participantes e se constituir como um espaço dialógico, que favoreça o desenvolvimento de uma consciência crítica.

Freire (2018), ao discorrer sobre a prática educativa libertadora e dialógica, ressalta que o ponto de partida da formação discente, que visa uma formação libertadora, devem ser os saberes de experiência dos educandos. Nessa concepção, o conteúdo programático dos processos de ensino e de aprendizagem deve compor o universo cultural discente. Em analogia às concepções freireanas, entendemos que o processo de formação continuada de professores, que visa uma formação crítica e reflexiva, também deve considerar, como ponto de partida, os saberes oriundos da experiência docente e, desse modo, os conteúdos programáticos dessa formação devem ser pensados em comunhão com os docentes.

\footnotetext{
${ }^{1}$ É importante ressaltar que a utopia na epistemologia freireana, conforme explica Freitas (2019), tem estreita relação com a compreensão de Bloch ([1950] 2005), pois o utópico não é o irrealizável, não é o idealismo; é a compreensão de que a realidade não é algo dado, imutável, mas está sendo e que, portanto, pode vir a ser transformada.

${ }^{2} \mathrm{Na}$ concepção freireana, a busca do ser mais é a vocação ontológica do ser humano, por meio da qual busca conhecer a si mesmo e ao mundo e luta por transformação (ZITKOSKI, 2019).
} 
Pautados nessa perspectiva, descrevemos, neste artigo, como um processo de formação continuada pode ser construído a partir de uma (re)leitura da epistemologia freireana e do trabalho desenvolvido nos círculos de cultura.

\section{CONSCIENTIZAÇÃO SEGUNDO A EPISTEMOLOGIA FREIREANA}

Segundo Freire (2020), o ser humano está no mundo e com o mundo. É um ser histórico, social, cultural e, portanto, é um ser capaz de relacionar-se, de humanizar-se e de conscientizar-se com o outro e com o mundo. Isso porque, para o autor, o ser humano é um ser da práxis - ato de ação-reflexão -, pois reflete e age para se transformar e transformar a realidade. Assim, a práxis é a unidade dialética entre a ação e a reflexão dos seres sobre o mundo.

Essa unidade dialética constitui, para Freire (2020), o modo de ser ou de transformar a realidade que caracteriza as mulheres e os homens. Todavia, transformar a realidade requer uma conscientização crítica do ser que, de acordo com o autor, não se dá naturalmente, mas por meio de um processo educativo de conscientização.

Mas, o que é a conscientização para a concepção freireana? A conscientização, nessa concepção, é o desenvolvimento crítico da tomada de consciência sobre os fatos, o vivido, a realidade. Contudo, a tomada de consciência ainda não é a conscientização, pois a "[...] conscientização implica que se passe da esfera espontânea de apreensão da realidade para uma esfera crítica, na qual a realidade se oferece como objeto cognoscível e na qual o homem assume um posicionamento epistemológico" (FREIRE, 2016, p. 56).

Por esse motivo, a conscientização não se resume em conhecer a realidade. Ela se constitui com a práxis, pois na medida em que o ser humano toma conhecimento da própria realidade e se compromete com sua transformação, ele/ ela vai se tornando consciente. A conscientização implica no desvelamento da realidade; quanto mais se conhece a realidade, mais conhecimento se produz a respeito dela. Essa tomada de consciência, que desvela a realidade, só autêntica a conscientização se "[...] a prática do desvelamento da realidade constitui uma unidade dinâmica e dialética com a prática da transformação da realidade" (FREIRE, 2019a, p. 244). Em outros termos, só a tomada de consciência não é suficiente para que haja a conscientização, é preciso atuar sobre a realidade para transformá-la, é preciso o ato de ação-reflexão (práxis).

No processo de conscientização, Freire $(1967,2020)$ apresenta três estados distintos da consciência: a consciência intransitiva, a consciência ingênua e a consciência crítica.

A consciência intransitiva "[...] resulta de um estreitamento no poder de captação da consciência [da realidade]. É uma escuridão a ver ou ouvir os desafios que estão mais além da órbita vegetativa do homem" (FREIRE, 2020, p. 51). Nesse estado de consciência, os indivíduos centram seus interesses em formas mais vegetativas de existência. Suas preocupações restringem-se ao que é necessário para a manutenção da vida e sua esfera de captação da realidade e apreensão dos problemas é limitada.

Segundo Freire (1967), mulheres e homens são capazes de captar os dados da realidade, com seus problemas, mas, também, de captar seus vínculos causais. Ao apreender essa causalidade, compreendem-na criticamente. Por outro lado, quando essa causalidade não é compreendida em profundidade, o indivíduo tem uma percepção mágica ou supersticiosa da realidade, pois está imerso na situação que lhe é posta.

Quando mulheres e homens são provocados a refletir sobre as questões que lhes são postas, inicia-se o processo de emersão da realidade. Nesse processo, ampliam seu poder de captação de 
seu entorno, logo a consciência intransitiva se promove em consciência ingênua. Contudo, essa nova consciência, é também mágica, pois

[...] se caracteriza, entre outros aspectos, pela simplicidade na interpretação dos problemas. Pela tendência a julgar que o tempo melhor foi o tempo passado. Pela subestimação do homem comum. Por uma forte inclinação ao gregarismo, característico da massificação. Pela impermeabilidade à investigação, a que corresponde um gosto acentuado pelas explicações fabulosas. Pela fragilidade na argumentação. Por forte teor de emocionalidade. Pela prática não propriamente do diálogo, mas da polêmica. Pelas explicações mágicas (FREIRE, 1967, p. 59).

Esse estado de consciência, apesar de ainda permanecer mágica, leva o indivíduo a uma busca pelo compromisso com a existência, que não é característico da consciência intransitiva. Por outro lado, há um risco de a consciência ingênua, que não se promove à consciência crítica, distorcer-se em consciência fanática pela tendência a aceitar formas massificadas de comportamento.

A respeito das mudanças de estado de consciência, Freire (2020) explica que a passagem da consciência intransitiva para a consciência ingênua, se dá naturalmente, a partir de alguma mudança, econômica, por exemplo, que pode ocorrer na comunidade. Em contrapartida, a passagem da consciência ingênua para a consciência crítica, conforme o autor, se dá por meio de um processo educativo de conscientização, que requer um trabalho de desvelamento da realidade e de critização.

Mas, como se caracteriza o estado de consciência crítica?

[...] se caracteriza pela profundidade na interpretação dos problemas. Pela substituição de explicações mágicas por princípios causais. Por procurar testar os "achados" e se dispor sempre a revisões. Por despir-se ao máximo de preconceitos na análise dos problemas e, na sua apreensão, esforçar-se por evitar deformações. Por negar a transferência da responsabilidade. Pela recusa a posições quietistas. Por segurança na argumentação. Pela prática do diálogo e não da polêmica. Pela receptividade ao novo, não apenas porque novo e pela nãorecusa ao velho, só porque velho, mas pela aceitação de ambos, enquanto válidos. Por se inclinar sempre a arguições (FREIRE, 1967, p. 60, grifo no original).

Nesse sentido, a consciência crítica, que é fruto de uma educação dialógica e conscientizadora, é a representação de como os fatos operam na experiência empírica e é a forma mais crítica de conhecer a realidade.

Conforme já mencionado, a passagem da consciência ingênua para a consciência crítica requer um processo educativo de conscientização. Mas não se trata de qualquer processo educativo que se diz conscientizador, se trata de um processo cuja prática educativa deve ser libertadora. Nessas condições, como podemos pensar o processo de conscientização na/para uma formação continuada de professores?

Para responder a essa questão, realizamos uma (re)leitura da epistemologia freireana no que diz respeito à metodologia adotada no círculo de cultura. Segundo Brandão (1991), o círculo de cultura é uma ideia que substitui o aspecto tradicional da sala de aula, pois os participantes se dispõem em círculo ao redor de companheiros ou de companheiras, que mediam o processo educativo. $\mathrm{O}$ mediador ou a mediadora orienta um trabalho em equipe buscando a participação do grupo em todos os momentos do diálogo. O diálogo no grupo visa a produção de modos coletivos de pensar, ensinar e aprender. E assim, a coletividade aprende que aquilo que constroem é uma outra forma de fazer a cultura que os faz, sujeitos e seres de história. O trabalho no círculo é 


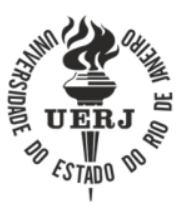

DOI: $10.12957 /$ teias.2021.62062

pensado e planejado com a coletividade, ou seja, a partir do diálogo entre mediadores e participantes.

A (re)leitura realizada nos indicou que o processo de conscientização na/para uma formação continuada de professores pode ser pensado, assim como no círculo, a partir de momentos de planejamento e de desenvolvimento, que denominados: investigação, tematização, problematizaçãa e conscientiz̧ação.

$\mathrm{Na}$ investigação, busca-se, por meio da relação dialógica com o outro, conhecer anseios, expectativas, dúvidas, ou seja, visões de mundo repletas de significados que implicam em temas, que constituirão a base do conteúdo programático. O que se pretende investigar não são as mulheres e os homens, "[...], mas o seu pensamento-linguagem referido à realidade, os níveis de sua percepção desta realidade, a sua visão do mundo, em que se encontram envolvidos seus 'temas geradores" (FREIRE, 2018, p. 121 - 122, grifo no original).

Em síntese, essa investigação implica:

[...] uma metodologia que não pode contradizer a dialogicidade da educação libertadora. Daí que seja igualmente dialógica. Daí que, conscientizadora também, proporcione, ao mesmo tempo, a apreensão dos “temas geradores" e a tomada de consciência dos indivíduos em torno dos mesmos (FREIRE, 2018, p. 121, grifo no original).

Por isso, a escolha dos temas não deve partir apenas dos mediadores do processo formativo, nem somente das necessidades dos participantes, mas, principalmente, das situações que o grupo vivencia, que quando compreendidas como barreiras instransponíveis, impossibilitam o agir do grupo. Assim, nos momentos do processo de conscientização, os temas devem ser propostos como problemas que, por sua vez, desafiam e exigem do grupo respostas, no nível intelectual e no nível da ação.

$\mathrm{Na}$ tematização, que caminha simultaneamente com a investigação, analisa-se o diálogo e constitui-se os temas com base nas situações apresentadas pelos participantes. A partir da investigação e da constituição dos temas, é possível construir coletivamente formas de (re)agir, de contrapor e de transformar as situações vivenciadas. Para tal, nos adentramos em um processo de problematização.

Conforme explica Mühl (2019, p. 383), “[a] problematização compreende o momento do desenvolvimento de uma consciência crítica sobre os temas em debate pela identificação de situações desafiadoras ou de problemas concretos que envolvam a vida dos alfabetizandos". $\mathrm{Na}$ nossa (re)leitura, pensando na formação de professores, a problematiæação é o momento em que as situações são apresentadas em forma de temas a serem dialogados com o grupo. O diálogo acerca dessas situações, segundo Freire (2018), é o momento da descodificação, ou seja, da análise crítica da situação codificada. Assim, na perspectiva do autor, a codificação de uma situação é a representação da situação em interação com seus elementos constitutivos e a descodificação é o momento em que a realidade é desvelada e busca-se o desenvolvimento crítico da tomada de consciência sobre as situações.

Em vista disso, a conscientização se dá no desenvolvimento crítico da tomada de consciência da realidade e do ato de ação-reflexão - práxis (FREIRE, 2020). A tomada de consciência que pode iniciar desde a investigação - quando os docentes começam a dialogar a respeito das situações vivenciadas -, se desenvolve com a problematização. Em consonância, o processo de conscientização, que se inicia desde a investigação, se concretiza a partir da práxis. Em outras palavras, a 
conscientização se desenvolve quando refletimos a respeito das situações e buscamos por meio de ações superá-las.

Os momentos do processo de conscientização apresentados descrevem como podemos pensar esse processo na/para uma formação continuada de professores, e representam possibilidades de se construir um processo formativo, que vise uma prática educativa libertadora.

\section{O CAMINHO METODOLÓGICO}

Esta investigação, conforme já mencionado, é parte de uma pesquisa de doutorado ${ }^{3}$ que possui abordagem qualitativa, segundo os princípios teóricos de Lüdke e André (1986), com características de pesquisa-ação, conforme Thiollent (2011).

A pesquisa foi realizada em uma Escola Estadual de Ensino Fundamental de São Paulo. O grupo investigado foi composto por cinco professoras dos anos iniciais do Ensino Fundamental, que doravante chamaremos pelos nomes fictícios de Clara, Mariinha, Vandi, Agnes e Carol ${ }^{4}$. O espaço de realização foi o destinado aos encontros de Aula de Trabalho Pedagógico Coletivo (ATPC). A ATPC é um espaço de formação continuada destinado a atividades pedagógicas extraclasse, que visam discutir, acompanhar e avaliar a proposta pedagógica da escola e o desempenho dos estudantes.

Para a realização dessa pesquisa, a Diretora da escola disponibilizou encontros quinzenais da ATPC. Assim, ao longo de nove meses, realizamos quinze encontros de ação de formação nos quais propusemos estudos sobre temas ${ }^{5}$ de interesse das docentes. Esses temas foram constituídos na fase exploratória da pesquisa, na qual as participantes relataram situações vivenciadas por elas no contexto educacional.

Os dados produzidos ao longo dos encontros de formação foram registrados em gravações de áudio e transcritos na íntegra. Para a análise dos dados selecionamos trechos dos diálogos das participantes e os identificamos como episódios. A interpretação desses episódios foi subsidiada pela Análise Dialógica do Discurso, proveniente dos estudos bakhtinianos.

Tendo em vista, que o foco desse artigo é apresentar as contribuições da epistemologia freireana na/para uma formação continuada, objetivamos, então, descrever como um processo de formação continuada pode ser construído a partir de uma (re)leitura da epistemologia freireana e do trabalho desenvolvido nos círculos de cultura. Para tal, relatamos como a ação de formação foi construída na fase exploratória e apresentamos um recorte do encontro seis em que o tema Dialogando sobre respeito aos diferentes saberes foi discutido.

\section{A CONSTRUÇÃO DA AÇÃO DE FORMAÇÃO}

A fase exploratória representa a investigação do processo de conscientização da epistemologia freireana. Essa fase se constituiu de um momento de apresentações da pesquisadora, da pesquisa, das professoras participantes e da busca dos temas.

\footnotetext{
${ }^{3}$ Esta pesquisa foi submetida ao Comitê de Ética em Pesquisa em Ciências Humanas e Sociais da Faculdade de Educação da Universidade Estadual de Campinas - Unicamp.

${ }^{4}$ Informamos que Carol não participou do encontro seis de formação, que será descrito neste artigo.

${ }^{5}$ Esses temas têm como base a perspectiva freireana de temas geradores (FREIRE, 2018), que representam percepções da realidade, visões de mundo das participantes.
} 
Com o intuito de conhecermos as perspectivas do grupo acerca da ação de formação e com o objetivo de captarmos, nas enunciações das docentes, possíveis temas a ser abordados na ação, convidamos as participantes a se expressarem a respeito de suas necessidades e expectativas. Por meio desse convite, objetivamos apreender o que Bakhtin (1997) denomina de atitude responsiva ativa $^{6}$, ou seja, o que as participantes compreendem e significam a respeito do discurso enunciado por nós. Em outros termos, buscamos apreender qual seria o tipo de atitude responsiva das participantes: concordância, discordância, complemento, silêncio etc.

$\mathrm{Na}$ ocasião, de imediato, o silêncio tomou conta do espaço. Tal atitude é entendida, na perspectiva bakhtiniana, como uma compreensão responsiva de ação retardada, como o que ocorreu, em seguida, quando a docente Vandi interrompeu o silêncio e enunciou: "Você vai deixar eu falar?". Tal enunciado interrogativo ecoou em nossos ouvidos como um pedido de liberdade, de estabelecimento de uma oportunidade de fala.

$\mathrm{Na}$ busca por compreender o(s) discurso(s) que está(ão) por trás desse enunciado, trazemos à tona o que Bakhtin e Voloshinov (1976) consideram a parte presumida do enunciado. Compreendemos que o que está presumido nesse enunciado, emitido com entoação serena e, ao mesmo tempo, em tom de reivindicação, é o desejo que Vandi tinha por ocupar o espaço de fala e não apenas o de escuta. A docente queria ser ouvida, precisava comunicar-se e comunicar seus anseios, seus temores, suas necessidades e suas expectativas a respeito do processo formativo que ali se iniciava. O que presumimos pode ser constatado a posteriori, pois, em sua atitude responsiva ativa, a docente falou sobre si, sobre o grupo, mas com o grupo e não para o grupo. Assim, Vandi, por meio de sua ação, tornou-se sujeita do processo dialógico.

Vale ressaltar que, quando fizemos o convite para que as docentes se expressassem, também almejávamos superar a verticalidade da relação entre pesquisadora e participantes, na qual, inúmeras vezes, é comum que pesquisadores assumam o papel de detentores do conhecimento que seria, então, absorvido pelas participantes. Sabíamos que essa superação só seria possível se compreendêssemos a leitura de mundo das participantes e respeitássemos os saberes advindos da experiência docente. Para isso, era preciso estabelecer uma relação dialógica com o grupo.

A fala de Vandi foi o ponto de partida para que as outras docentes também se expressassem e relatassem não apenas as expectativas acerca da ação de formação, como também situações que vivenciavam no contexto educacional, no qual estavam inseridas. Essas situações se configuravam, para as participantes, como barreiras ao desenvolvimento da autonomia e da liberdade na prática pedagógica. Das situações apresentadas pelas docentes ao longo da fase exploratória, destacamos as seguintes: falta de autonomia e ausência de identidade docente no planejamento e na execução das aulas de Matemática; possivel falta de confiança e de valorização dos saberes que as docentes possuem; limitação do material didático no que diz respeito às atividades e aos conteúdos; e obrigatoriedade em trabalhar com atividades apresentadas no material didático adotado pelo sistema de ensino, seguindo a sequência proposta no material.

Compreendemos que essas situações que causam acomodações ou rupturas, que provocam estranhamento ou insatisfações, se caracterizam como situaçôes-limite que representam a fronteira entre o ser e o ser mais, portanto não são essas situações, “[...] em si mesmas, geradoras de um clima de desesperança, mas a percepção que os homens tenham delas num dado momento histórico, como um freio a eles, como algo que eles não podem ultrapassar"' (FREIRE, 2018, p. 126).

Nesse sentido, precisávamos de uma ação de formação que fosse capaz de promover o aprofundamento da tomada de consciência das situações e desenvolver um clima de confiança nas

${ }^{6}$ A compreensão responsiva, para Bakhtin (1997, p. 292), “[...] nada mais é senão a fase inicial e preparatória para uma resposta (seja qual for a forma de sua realização)". 
docentes para que se empenhassem na superação das situações-limite, por meio dos atos-limite que, para Freire (2018, p. 126, grifo no original), "[...] implicam uma postura decisória frente ao mundo, do qual o ser se 'separa', e, objetivando-o, o transforma com sua ação".

Dessa forma, conhecendo as situações-limite apresentadas pelas participantes iniciamos a tematização. Nesse momento, analisamos os diálogos das docentes nos encontros da fase exploratória, identificamos as situações e, a partir delas, construímos temas a ser dialogados nos encontros de formação. Os diálogos acerca desses temas seriam o ponto de partida para a problematização, na qual buscamos um aprofundamento crítico acerca das situações vivenciadas, almejando a superação de uma visão acrítica e a construção coletiva de ações para a conscientização do grupo.

\section{DIALOGANDO SOBRE RESPEITO AOS DIFERENTES SABERES}

O tema desse encontro emergiu a partir da situação-limite - uma possivel falta de confiança e de valorização dos saberes que as docentes possuem - apresentada pelas participantes na fase exploratória. Contudo, ao pensar nessa temática voltamos nosso olhar para a falta de valorização dos saberes que os estudantes possuem. $\mathrm{O}$ intuito dessa analogia foi refletir sobre como agir em situações respeitando os diferentes saberes no contexto de sala de aula e, com isso, tomar distância epistemológica do fato vivido por elas para, então, analisá-lo sob o ponto de vista de quem se depara com esses diferentes saberes e precisa respeitá-los.

Cabe salientar que quando falamos em valorizar os saberes da experiência não estamos dizendo que o ensino deve se resumir a esses saberes, mas que essa valorização deve ocorrer ao mesmo tempo em que se promove a capacidade criadora dos estudantes em busca da produção de novos saberes.

Nesse contexto, apresentamos como se desenvolveu o diálogo no encontro seis. Para tal, realizamos um recorte de trechos desses diálogos que serão descritos em três episódios.

\section{Discussões e resultados}

Planejamos para o encontro seis a leitura dos quatro primeiros capítulos do livro $O$ menino do dedo verde, do autor Maurice Druon. O menino do dedo verde é uma história fictícia de um menino chamado Tistu, que nasceu em família rica e mesmo com todos os privilégios que uma família com tal condição possui, não obteve sucesso na escola. Tistu iniciou seus estudos em casa com sua mãe. Quando Tistu completou oito anos, sua mãe considerou que era necessário que ele fosse para uma escola e continuasse os estudos com um professor. Mas o desfecho não foi como o esperado, conforme retrata o trecho do livro, a seguir:

[...] A escola produziu em Tistu um resultado imprevisível e lamentável.

Quando começava o lento desfile das letras que caminham a passo pelo quadronegro, quando começava a se desenrolar a monótona corrente dos três-vezestrês, dos cinco-vezes-cinco, dos sete-vezes-sete, Tistu sentia uma coceira no olho esquerdo e logo caía no mais profundo sono.

Não é que ele fosse burro ou preguiçoso, nem que estivesse cansado. Estava cheio da maior boa vontade.

"Eu não quero dormir, eu não quero dormir", repetia Tistu consigo mesmo.

Pregava os olhos no quadro e colava os ouvidos à voz do professor. Mas sentia que a coceirinha estava chegando... Tentava, por todos os meios, lutar contra o sono. Cantava bem baixinho uma bela canção que inventara: 
Um quarto de andorinha...

Será a sua pata

ou será uma asinha?

Se fosse uma empada,

eu comia todinha!

Não adiantava. A voz do professor ia se transformando numa canção de ninar; a noite descia sobre o quadro-negro; Tistu ouvia o teto cochichar: "Por aqui, por aqui, belos sonhos!", e a aula se transformava em aula de sonhar.

— Tistu! - gritava de repente o professor.

- Não foi de propósito, Professor — respondia Tistu, acordando num sobressalto.

— Isso não interessa. Repita o que acabo de dizer.

— Seis empadas... divididas por duas andorinhas ...

- Zero!

No primeiro dia de aula Tistu voltou para casa com o bolso repleto de zeros.

No segundo dia, ficou de castigo por mais duas horas, isto é, ficou mais duas horas a dormir na aula.

$\mathrm{Na}$ tarde do terceiro dia, o professor entregou a Tistu uma carta para seu pai.

$\mathrm{Na}$ dita carta o Sr. Papai teve a desdita de ler estas palavras:

"Prezado Senhor, o seu filho não é como todo mundo. Não é possível conserválo na escola."

A escola devolvia Tistu a seus pais

(DRUON, 1992, p. 20 - 21, grifo no original).

Após a leitura, propusemos às docentes que refletissem sobre a situação de Tistu e, em seguida perguntamos: O que vocês observam do comportamento do professor?

Agnes: $O$ professor percebia que o menino estava a cochilar, pois ele não entendia as lições. Então o professor gritava e pedia para ele repetir tudo, e ele se sentia ainda mais fora daquela realidade. E, no final, o professor devolveu o menino.

Clara: Na minha opinião, o professor deveria ter mais paciência com Tistu e era muito cedo para devolvê-lo aos pais. Eles tinham que dar uma sondada nesse menino.

Agnes: Tinha que ensinar ele lá [na escola], porque as coisas que aprendeu com a mãe não eram as mesmas ensinadas na escola.

Mariinha: O professor ficou irritado com Tistu, porque ele se mostrava muito sem interesse e muito apático. Ele ficava às vezes com vergonha ou com medo, porque aprendeu com a mãe. Talvez de modo diferente, de modo tradicional e o professor talvez estivesse ensinando de outro modo, e Tistu ficou perdido. Aí o professor já foi ficando irritado com aquela situação.

Vandi: Eu entendi a pergunta por um outro prisma. Eu observei o comportamento do professor. Ele ignorou completamente os conhecimentos prévios do aluno e seu conhecimento de mundo [...]. Esse professor teve essa questão conflituosa, ele ignorou totalmente o que o menino sabia. O menino dividia até andorinha, a perna, a asa, 1/4, ele já sabia até fração, ele estava na frente. Então, quando ele chegou na escola, a escola estava totalmente fora da realidade dele, não era nem uma despreparação, a escola estava preparada, mas não para a realidade do menino.

(EPISÓDIO 01) 
Objetivamos, com essa pergunta, conhecer o olhar das docentes em relação ao comportamento do professor e, ao mesmo tempo, compreender a base de seus discursos ao analisar a partir de qual ponto de vista as docentes observariam o fato ocorrido.

Agnes e Mariinha analisam a situação do ponto de vista do aluno ao expressar como o aluno se sentiu diante da situação vivenciada: "[...] ele se sentia ainda mais fora daquela realidade" (AGNES); "[...] ele ficava às vezes com vergonha ou com medo, porque aprendeu com a mãe" (MARIINHA). O aluno estava fora da realidade do contexto escolar, pois o professor, conforme destaca Vandi, "[...] ignorou totalmente o que o menino sabia". Tal atitude é característica de um educador bancário, que, na sua antidialogicidade, não se pergunta em torno do que vai dialogar com os estudantes, "[...], mas a respeito do programa sobre o qual dissertará a seus alunos" (FREIRE, 2018, p. 116).

A entoação da $\mathrm{voz}^{7}$ no discurso de Agnes, ao enunciar "[...] tinha que ensinar ele lá [...]", revela sua indignação com o professor por ter devolvido Tistu à família. $\mathrm{O}$ mesmo ocorre no discurso de Clara, quando enuncia que "[...] o professor deveria ter mais paciência com Tistu [...]".

A respeito do discurso de Mariinha, a docente busca compreender o que ocorre em ambos os lados. A postura de Mariinha é de escuta ao justificar por que o professor ficava irritado e por que Tistu não aprendia: "[...] o professor talvez estivesse ensinando de outro modo, e Tistu ficou perdido".

Por fim, Vandi, em seu discurso, direciona o foco de sua análise para o comportamento do professor. Em suas enunciações deixa a entender sua contraposição à educação bancária, que ignora os conhecimentos prévios dos alunos e seu conhecimento de mundo. Além disso, reconhece que, apesar de a escola estar preparada para o ensino, ela não está preparada para todas as realidades. Essa percepção mostra que a escola, enquanto sistema de educação, também é um "ser" inconcluso, uma vez que é constituída por seres inacabados (FREIRE, 2018). agiriam?

Em continuidade ao diálogo, perguntamos às docentes: E nessa situação, como vocês

Agnes: Eu procuraria acolher o menino, não gritaria com ele, procuraria alavancar ele, pegar o conhecimento do mundo e inseri-lo lá.

Clara: Eu ia ver o que Tistu já sabia e depois chamaria os pais para ter uma conversa e não já ir devolvendo o pobrezinho.

Mariinha: Com certeza, eu tentaria chamar a atenção dessa criança, talvez conversando com ele para saber se ele já estudou em outra escola, tentando fazer com que ele se socializasse, interagisse com as demais crianças e com o professor. Vandi: Mesmo eu sendo uma professora que leva uma carga de conservadorismo bem forte com relação ao ensino e à aprendizagem, não me sinto confortável ao perceber uma atitude de indiferença de um aluno quando estou ensinando. Nessa situação, conversaria com o aluno investigando o motivo do desinteresse. Em conversas francas e bem pensadas nós professores conseguimos descobrir a origem de tamanha apatia e desinteresse.

(EPISÓDIO 02)

A pergunta teve como intuito trazer à tona a reflexão de que situações semelhantes à de Tistu podem ocorrer no contexto de sala de aula que as docentes estão inseridas. Portanto, refletir sobre a ação (SCHON, 2000), mesmo diante de uma situação fictícia, possibilita a compreensão e a reconstrução da prática.

\footnotetext{
${ }^{7}$ Agnes altera um pouco a voz, ela fala mais alto que de costume e expressa indignação.
} 
Dando continuidade ao diálogo com os discursos, observamos, no enunciado de Agnes “[eu] procuraria acolher o menino, não gritaria com ele, procuraria alavancar ele [...]", que a docente expressa uma preocupação em acolher e incentivar o aluno. Agnes revela uma postura de educadora que pensa certo. Para Freire (2019b, p. 36), "[...] faz parte do pensar certo o gosto da generosidade que, não negando a quem o tem o direito à raiva, a distingue da raivosidade irrefreada". Nesse viés, acolher e incentivar são atitudes de quem tem gosto pela generosidade e o ato de gritar se caracteriza como raivosidade irrefreada.

Outra característica de educadores que pensam certo é a abertura ao diálogo. Observamos, nos enunciados de Clara e de Mariinha, que as docentes se encontram abertas ao diálogo: Clara ao enunciar "[eu] ia ver o que Tistu já sabia e depois chamaria os pais para ter uma conversa [...]" e Mariinha ao enunciar "[...] tentaria chamar a atenção dessa criança, talvez conversando com ele para saber se ele já estudou em outra escola [...]”.

A respeito do discurso de Vandi, observamos que a docente inicia seu enunciado utilizando como signo ideológico a palavra conservadorismo e que ao enunciar "[...] mesmo eu sendo uma professora que leva uma carga de conservadorismo bem forte com relação ao ensino e à aprendizagem [...]", estabelece uma relação dialógica entre os valores sociais que a orientam e os valores sociais que a contrapõem (VOLÓCHINOV, 2018). Essa relação se estabelece, pois, por não se sentir "[...] confortável ao perceber uma atitude de indiferença de um aluno" quando está ensinando, ela denota uma abertura ao diálogo ao enunciar "[...] conversaria com o aluno investigando o motivo do desinteresse", mesmo levando uma carga de conservadorismo bem forte. No último trecho do episódio:

Agnes: As nossas mães lá no sítio, na área rural, ensinavam quantos pés de café, quantas canas, quantas laranjas, quantos milhos tinham.

Clara: A gente aprendia né.

Vandi: Minha mãe semianalfabeta conseguiu alfabetizar todos os filhos e olha que eu aprendi mais cedo. Com 6 anos de idade eu já lia, porque ela estava ensinando a minha irmã mais velha e eu ficava por perto e aprendia. É igual a Agnes falou, eu me lembro de contar caroço de milho. Então, conta a gente sabia, porque já tinha aquele conhecimento e quando chegava na escola a gente já sabia e sabia bem. Hoje em dia não é esse o conhecimento de mundo que a criança traz.

Pesquisadora: Mas, vejam, estamos em outro momento, temos outros recursos. O que utilizamos no passado é importante para o processo de construção histórica, mas também precisamos nos mover enquanto tempo presente [...]. Nesse tempo presente qual o conhecimento de mundo que a criança traz? Agnes: Agora eles sabem melhor do que a gente a mexer no computador. Pesquisadora: E esse conhecimento de mundo é aproveitado pela escola? Mariinha: Às vezes, quando trazemos eles para a sala de vídeo que tem os computadores. Aí eles mexem, pesquisam, sabem mais do que a gente.

Pesquisadora: O que seria necessário para que o "às vezes" fosse algo mais frequente?

Agnes: Mais recursos. Computadores com internet boa e funcionando. O que temos aí foi doado, senão nem teríamos.

Pesquisadora: E o recurso financeiro que é destinado para a escola não daria para atender a essas necessidades?

Clara: É muito pouco.

$[\ldots]$

(EPISÓDIO 03) 
Consideramos relevante apresentar este último trecho do diálogo, pois ele mostra, em seu início, com os discursos de Agnes, Clara e Vandi, característica da consciência que Freire (2020) denomina de consciência ingênua. Isso ocorre pois nos discursos há uma tendência em considerar que os ensinamentos do passado proporcionavam uma aprendizagem que os ensinamentos de hoje não proporcionam. No enunciado de Clara "[a] gente aprendia né", por exemplo, o discurso da docente pode possibilitar a compreensão de que no passado as crianças aprendiam e hoje não aprendem.

A perspectiva de recorrer ao passado não leva em consideração que estamos em outro momento da história, onde os recursos disponíveis diferem dos recursos disponíveis na época que as docentes estudaram e, por isso, trouxemos a discussão para o momento atual. Ao perguntamos qual o conhecimento de mundo que a criança traz, Agnes sinaliza compreender o nosso discurso sob a perspectiva que queríamos e enuncia "[...] agora eles sabem melhor do que a gente a mexer no computador".

A reflexão que trouxemos em pensar o presente sem desconsiderar a importância do passado fez com que as docentes refletissem sobre a bagagem de conhecimentos que os estudantes de hoje possuem, superando assim, a nosso ver, a percepção ingênua que tinham a respeito dos ensinamentos do passado. Além disso, fez com que Agnes expressasse sua condição de ser inacabado (FREIRE, 2019b), que se reconhece como tal ao enunciar que os estudantes sabem melhor do que a gente a mexer no computador. Assim como, a reflexão oportunizou às docentes $\mathrm{o}$ ato de pensar nas situações-limite que a escola vivencia pela falta de recursos didáticos e financeiros.

Podemos observar que todo o diálogo se alicerça nas experiências vivenciadas no contexto de sala de aula. A situação fictícia apresentada na obra de Druon (1992) foi só o ponto de partida para fomentar reflexões sobre como podemos agir em diferentes situações-problema que enfrentamos cotidianamente. Esse pensar coletivo, mesmo que ocorra pelo pensar individual de cada componente do grupo, viabiliza o compartilhamento de ideias e de formas de saber-fazer.

O recorte apresentado exemplifica como nos inserimos na problematização do processo de conscientização da epistemologia freireana. Nesse momento do processo, buscamos, por meio do diálogo com as docentes, construir uma visão crítica acerca de uma situação em que a sala de aula se torna um espaço antidialógico no qual o saber do estudante não é valorizado.

Ao perguntarmos o que elas fariam nessa situação, buscamos produzir atos-limite, ou seja, pensar em ações que poderiam ser executadas em sala de aula caso situações como esta aconteça. Com isso, almejamos viabilizar o ato de ação-reflexão, que se constituiu a partir da conscientizạ̧ão.

\section{CONSIDERAÇÕES FINAIS}

A diversidade do legado epistemológico de Paulo Freire possibilita a realização de inúmeras (re)leituras, pois devido a fecundidade de seu referencial, é possível (re)criar interpretações na atualidade. Em vista disso, uma das possibilidades que encontramos foi (re)criar interpretações desse legado epistemológico na/para uma formação de professoras dos anos iniciais do Ensino Fundamental.

Portanto, nesta pesquisa, para a (re)leitura que realizamos, a epistemologia freireana contribuiu para a construção de um processo de formação continuada desde o planejamento até o desenvolvimento da ação formativa, tendo como base os momentos do processo de conscientização e o trabalho desenvolvido nos círculos de cultura. Na etapa de planejamento, conforme já descrito, os temas a ser dialogados nos encontros de formação emergiram a partir das 
situaçoes-limite vivenciadas e apresentadas pelas participantes. Na etapa de desenvolvimento, buscamos problematizar essas situações-limite por meio dos temas constituídos.

Outra contribuição que a epistemologia freireana proporcionou na/para uma formação foi a tomada de consciência das condições nas quais as professoras se encontravam em seu contexto escolar. Isso, tanto no que diz respeito aos seus relatos na fase exploratória, quanto em relação às enunciações a respeito da falta de recursos didáticos e financeiros no encontro seis.

Por fim, consideramos que os resultados mostraram que construir uma formação continuada, com base nos pressupostos da epistemologia freireana, pode possibilitar uma tomada de consciência da realidade, por meio da superação de uma visão acrítica acerca das situações-limite vivenciadas no contexto escolar, bem como o desenvolvimento de atos-limites para a superação dessas situações e para a construção de uma consciência crítica.

\section{REFERÊNCIAS}

BAKHTIN, Mikhail. Estética da criação verbal. Tradução: Maria Ermantina Galvão G. Pereira. 2. ed. São Paulo: Martins Fontes, 1997.

BAKHTIN, Mikhail.; VOLOSHINOV, Valentin. Discurso na vida e discurso na arte. Tradução: Cristóvão Tezza e Carlos Alberto Faraco. Texto de circulação acadêmica, 1976. Disponível em: Discurso na vida e discurso na arte - Google Acadêmico. Acesso em 15 de ago. 2020.

BLOCH, Ernst. O princípio da esperança. Rio de Janeiro: EdUERJ/Contraponto, 2005.

BRANDÃO, Carlos Rodrigues. O que é Método Paulo Freire. $17^{\circ}$ ed. São Paulo: Brasiliense, 1991.

DRUON, Maurice. O menino do dedo verde. Tradução: Dom Marcos Barbosa. Rio de Janeiro: José Olympio, 1992.

FREIRE, Paulo. Educação como prática da liberdade. Rio de Janeiro: Paz e Terra, 1967.

FREIRE, Paulo. Pedagogia da Esperança: um reencontro com a pedagogia do oprimido. $14^{\circ}$ ed. São Paulo: Paz e Terra, 2007.

FREIRE, Paulo. Conscientização. Tradução: Tiago José Risi Leme. São Paulo: Cortez, 2016.

FREIRE, Paulo. Pedagogia do oprimido. 66 ed. Rio de Janeiro/São Paulo: Paz e Terra, 2018.

FREIRE, Paulo. Ação cultural para a liberdade e outros escritos. $17^{\circ} \mathrm{ed}$. Rio de Janeiro/São Paulo: Paz e Terra, 2019a.

FREIRE, Paulo. Pedagogia da autonomia: saberes necessários à prática educativa. $58^{\circ}$ ed. Rio de Janeiro/São Paulo: Paz e Terra, 2019b.

FREIRE, Paulo. Educação e Mudança. Tradução: Lilian Lopes Martin. $41^{\circ}$ ed. Rio de Janeiro/São Paulo: Paz e Terra, 2020.

FREITAS, Ana Lúcia Souza. Utopia. In: STRECK, Danilo; REDIN Euclides.; ZITKOSKI, Jaime José (Org.). Dicionário Paulo Freire. 4. ed. Belo Horizonte: Autêntica Editora, 2019. p. 481 482.

LÜDKE, Menga; ANDRÉ, Marli. Pesquisa em educação: abordagens qualitativas. São Paulo: EPU, 1986.

MÜHL, Eldon Henrique. Problematização. In: STRECK, Danilo; REDIN Euclides; ZITKOSKI, Jaime José (Org.). Dicionário Paulo Freire. 4. ed. Belo Horizonte: Autêntica Editora, 2019. p. 383 384. 
SCHON, Donald. Educando o profissional reflexivo: um novo design para o ensino e a aprendizagem. Tradução: Roberto Cataldo Costa. Porto Alegre: Artmed, 2000.

STRECK, Danilo. Esperança. In: STRECK, Danilo; REDIN Euclides.; ZITKOSKI, Jaime José (Org.). Dicionário Paulo Freire. 4. ed. Belo Horizonte: Autêntica Editora, 2019. p. 198 - 199.

THIOLLENT, Michel. Metodologia da pesquisa-ação. 18º. ed. São Paulo: Cortez, 2011.

VOLÓCHINOV, Valentin. Marxismo e filosofia da linguagem: problemas fundamentais do método sociológico na ciência da linguagem. Tradução: Sheila Grilo e Ekaterina Vólkora Américo. 2. ed. São Paulo: Editora 34, 2018.

ZITKOSKI, Jaime José. Ser mais. In: STRECK, Danilo; REDIN Euclides.; ZITKOSKI, Jaime José (Org.). Dicionário Paulo Freire. 4. ed. Belo Horizonte: Autêntica Editora, 2019. p. 426 - 427.

\section{Informações do(a)(s) autor(a)(es)}

Mariana dos Santos Cezar

Universidade Estadual de Campinas - Unicamp

E-mail:marianascezar@hotmail.com

ORCID: https://orcid.org/0000-0002-9896-9041

Link Lattes: http:// lattes.cnpq.br/ 6684778801921463

Samuel Rocha de Oliveira

Universidade Estadual de Campinas - Unicamp

E-mail:samrocha@unicamp.br

ORCID: https://orcid.org/0000-0001-9219-1112

Link Lattes: http://lattes.cnpq.br/9839813543918575 